\title{
Five years of the Journal of Civil Structural Health Monitoring
}

\author{
Farhad Ansari ${ }^{1}$
}

Published online: 29 February 2016

(c) Springer-Verlag Berlin Heidelberg 2016

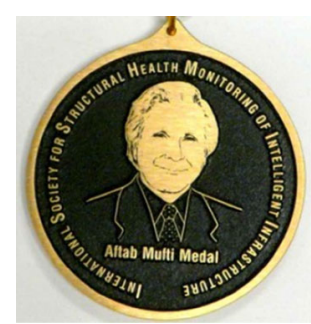

Let me begin by wishing the Journal of Civil Structural Health Monitoring (JCSHM) a very happy birthday. JCSHM is now 5 years old! The journal has come a long way since its humble beginnings in 2011. The first volume of JCSHM had two issues with a total of 124 pages, whereas volume number five in 2015 was comprised of 5 issues and 765 pages. We will readily surpass 1000 pages in 2016, and increase the number of issues in 2017. JCSHM is dedicated to publishing practice-oriented articles and specifically aims at providing technical information about the state-of-practice and technologies of importance for maintenance and safety of all types of civil infrastructure systems. This is a niche that the journal has consistently filled and no other journals have been able to publish articles specific to best practices in technologies impacting the discipline of Civil Structural Health Monitoring. We owe this success to the authors, reviewers, and the editorial board consisting of 17 members from 10 different countries that are internationally recognized as experts in the field of civil structural health monitoring. The board members strive to deliver a journal that includes high-quality, peerreviewed articles.

\footnotetext{
Farhad Ansari

fansari@uic.edu

1 University of Illinois, Chicago, USA
}

JCSHM is the brainchild of ISHMII, which is an international society with global perspective to advance the understanding and the application of civil structural health monitoring. Membership covers a broad range of engineers and practitioners, members of the academic community, and infrastructure managers and students. The high standards set by ISHMII have been essential and will sed range of engineers and practitioners, members of the academic community, and infrastructure managers and students. The high standards set by ISHMII have been essential and will serve as a guiding light for the expansion of journal contents.

JCSHM recognizes excellence, and awards the authors of the best paper from each volume with the Aftab Mufti Medal. The medal has been awarded four times since its inception in December 2011. The Aftab Mufti Medal honors the service, dedication, and lifetime achievements of Dr. Aftab Mufti, cofounder and the first president of ISHMII.

To celebrate JCSHM's 5 years of existence, we will be publishing state-of-the-art articles in several issues of volume six in 2016. Due to the interdisciplinary expertise and interests of the journal's readers, we anticipate that the sixth volume will provide an invaluable resource for researchers and practitioners in civil structural monitoring. Six of the state-of-the-art articles are published in this issue of the journal, covering a wide spectrum of topics of interest to our readers. These topics include monitoring of complex civil infrastructure systems, wireless smart sensors, cable-stayed bridges, bridge weigh-in-motion systems, experiences in monitoring of heritage structures in Italy, and inverse problems in vehicle-bridge interaction dynamics. In addition to the state-of-the-art articles, the regular papers in this first issue cover topics such as piezoelectric sensors for detection of cracks in concrete 
structures, deterministic as well as probabilistic damage detection methods for structural systems, and localization of damage in bridges. State-of-the-art papers covering other topics of interest to CSHM community will be published in the ensuing issues of volume six. I sincerely hope that our readers enjoy all of the articles. Thank you for playing a crucial role in JCSHM's success. 